Bài báo khoa học

\title{
Định giá tài nguyên nước đồng bằng sông Hồng trong bối cảnh biến đổi khí hậu
}

\author{
Trương Vân Anh ${ }^{*}$, Nguyễn Ngọc Thanh ${ }^{1}$, Hoàng Thị Huê1, Đỗ Văn Quang ${ }^{2}$, Nguyễn \\ Đức Dương1, Bùi Anh Tú ${ }^{2}$ Vũ Ngọc Luân ${ }^{2}$
}

${ }^{1}$ Hanoi University of Nature resources and Environment; nnthanh@hunre.edu.vn; tvanh@hunre.edu.vn; hthue@hunre.edu.vn

2 Thuy Loi University; quangkttl@tlu.edu.vn

*Tác giả liên hệ: tvanh@hunre.edu.vn; Tel.: +84-981479299

Ban Biên tập nhận bài: 8/4/2021; Ngày phản biện xong: 18/6/2021; Ngày đăng bài: 25/9/2021

Tóm tắt: Nước là một nguồn tài nguyên thiên nhiên đặc biệt, thiết yếu cho mọi sự sống trên trái đất nhưng cũng cần thiết cho phát triển nhiều ngành kinh tế chủ chốt của mỗi vùng miền. Nước cũng là nơi tiếp nhận các nguồn xả thải để trở nên bị nhiễm bẩn đến không còn khả năng là nguồn cấp cho các yêu cầu sử dụng nước khác, gây ra sự khan hiếm nước do phát triển KTXH ở ngay những nơi có nguồn tài nguyên nước dồi dào. Định giá TNN đang là một trong những công cụ giúp các nhà hoạch định chính sách có thể quản lý tổng hợp TNN một cách bền vững hơn thông qua việc cân bằng giữa chi phí sản xuất, bao gồm cả chi phí xử lý xả thải, và giá nước để có thể có được những dịch vụ về nước tốt hơn trong tương lai. Bài báo này đề xuất phương pháp định giá $\mathrm{TNN}$ đồng bằng sông Hồng, có xét đến những tác động của $\mathrm{BĐKH}$ ảnh hưởng đến chi phí cũng như cơ hội sử dụng nước của ngành công nghiệp, nông nghiệp và nước cấp sinh hoạt.

Từ khóa: Định giá tài nguyên nước; Biến đối khí hậu; Quản lý tài nguyên nước; Kinh tế nước; Mức sẵn lòng chi trả.

\section{1. Đặt vấn đề}

Ở Việt Nam cũng như nhiều nước đang phát triển khác, các nhà hoạch định chính sách đang phải đối mặt với tình trạng khan hiếm nước do phát triển kinh tế xã hội dẫn đến sự suy giảm nguồn cung nước trên đầu người [1]. Để giải quyết vấn đề này, phương pháp truyền thống chỉ dựa vào nâng cao hiệu quả nguồn cung, từ đó chính phủ các nước cố gắng đầu tư vào cơ sở hạ tầng cấp nước dẫn đến sự giải quyết không triệt để vấn đề khan hiếm nước đến từ cả hai phía là cung và cầu [2-3]. Trong trường hợp này, định giá tài nguyên nước, coi nước như một loại hàng hoá có giá trị kinh tế, là giải pháp mà các quốc gia phát triển đang sử dụng làm công cụ giúp các nhà ra quyết định đưa ra được những chính sách phù hợp trong việc quản lý nguồn tài nguyên nước cho sự phát triển bền vững của toàn lưu vực sông [3-5]. Theo rất nhiều nghiên cứu như $[3-4,6]$, định giá nước chính là phương tiện giúp các chính quyền thực hiện các chính sách công về nước.

Theo đó, định giá nước một cách công bằng và bình đẳng là điều quan trọng để duy trì và mở rộng hệ thống nguồn nước và đảm bảo an toàn vệ sinh. Ở nhiều quốc gia, người tiêu dùng trả quá ít tiền cho các dịch vụ cấp nước. Doanh thu từ tiền nước thậm chí còn không bao gồm chi phí vận hành và bảo trì các công trình cấp nước, chứ chưa nói đến đầu tư cho phát triển cơ sở hạ tầng dẫn đến nguồn nước cấp không đảm bảo vệ sinh hay tiêu chuẩn về chất lượng không đáp ứng được các yêu cầu dùng nước hoặc không đủ nguồn nước sạch cấp cho các nhu cầu thường xuyên [7]. Do vậy, thông thường biểu giá nước và nước thải giúp 
xác định mức doanh thu mà các nhà cung cấp dịch vụ nhận được từ người sử dụng trong các hệ thống tập trung hoặc bán tập trung để xử lý, làm sạch và phân phối nước ngọt thích hợp, cũng như đảm bảo việc thu gom, xử lý và xả nước thải sau đó. Điều này cần đảm bảo ngay cả trong những hệ thống có nguồn tài nguyên nước dồi dào. Tuy nhiên, vì nước là một nguồn tài nguyên đặc biệt, không có nước thì không có sự sống, nên việc coi nước là một loại hàng hoá như các loại tài nguyên thiên nhiên khác (dầu, than, gỗ...) trong một thị trường truyền thống sẽ dẫn đến không sự phân bổ kém hiệu quả và không công bằng. Do vậy, việc lựa chọn phương pháp tiếp cận trong định giá tài nguyên nước ở các quốc gia, thậm trí vùng miền, sẽ rất khác nhau. Và việc lựa chọn được phương pháp tiếp cận phù hợp với điều kiện địa phương sẽ là công cụ hữu hiệu giúp cho các nhà ra quyết định quản lý bền vững nguồn tài nguyên quý giá này mà vẫn đảm bảo phát triển hiệu quả kinh tế xã hội ở địa phương. Bài báo này phân tích điều kiện hiện trạng và đề xuất phương pháp định giá tài nguyên nước cho đồng bằng sông Hồng trong bối cảnh biến đổi khí hậu. Theo đó tác động của $\mathrm{B} Đ K H$ đến cả cung và cầu trong hệ thống được đề xuất xem xét trong quy trình xác định các phương pháp thực hiện cho phù hợp với điều kiện hiện nay ở Việt Nam.

\section{Phương pháp nghiên cứu và thu thập tài liệu}

\subsection{Giới thiệu về khu vục nghiên cưu}

Việt Nam có hai đồng bằng lớn: đồng bằng sông Hồng ở phía bắc và đồng bằng sông Cửu Long ở phía nam. Đồng bằng sông Hồng nằm ở phía Bắc Việt Nam, được coi là khu vực đông dân cư nhất của đất nước khoảng 22,62 triệu dân sống tập trung trên diện tích khoảng $21.260 \mathrm{~km}^{2}$ và chỉ 8,13 triệu trong số đó sống ở các thành phố. Mật độ dân số trung bình đạt 1.064 người/ $\mathrm{km}^{2}$ [8], trong đó một phần đáng kể làm việc trong lĩnh vực trồng trọt. Mặc dù có mật độ dân số cao, đồng bằng sông Hồng đã trải qua sự tăng trưởng nhân khẩu học đáng kể trong những năm 1950, với dân số tăng từ 6,5 triệu lên hơn 22 triệu cho đến nay; đồng thời, sản lượng nông nghiệp ghi nhận mức tăng đáng kể. Việc mở rộng sản xuất trang trại đó diễn ra trên các trang trại quy mô rất nhỏ: hai triệu rưỡi trang trại hiện có diện tích trung bình 0,28 ha cho hai hoặc ba lao động, và diện tích đất canh tác trên đầu người khoảng $630 \mathrm{~m}^{2}$ đất. Đồng bằng sông Hồng hiện sản xuất $20 \%$ sản lượng nông nghiệp của cả nước, lượng nuôi trồng thuỷ sản chiếm $9 \%$, nhu cầu nước công nghiệp chiếm $50 \%$ trên tổng nhu cầu của cả nước và thuỷ điện đóng góp khoảng $37 \%$ vào sản lượng điện quốc gia. Nhu cầu nước tăng cao trong hiện tại và tương lai làm tăng áp lực lên nguồn cung cấp nước, đòi hỏi phải có một cách quản lý bền vững, đảm bảo sự phát triển lâu dài cho nguồn nước ở đây. Trong nghiên cứu này, định giá $\mathrm{TNN}$ đồng bằng sông Hồng trong bối cảnh $\mathrm{BĐKH}$ sẽ là một trong những công cụ đắc lực giúp các nhà ra quyết định có cái nhìn tổng quát chung về cungcầu của sử dụng nước trong điều kiện hiện trạng và tương lai để có thể đưa ra những quyết sách quản lý bền vững nguồn tài nguyên này.

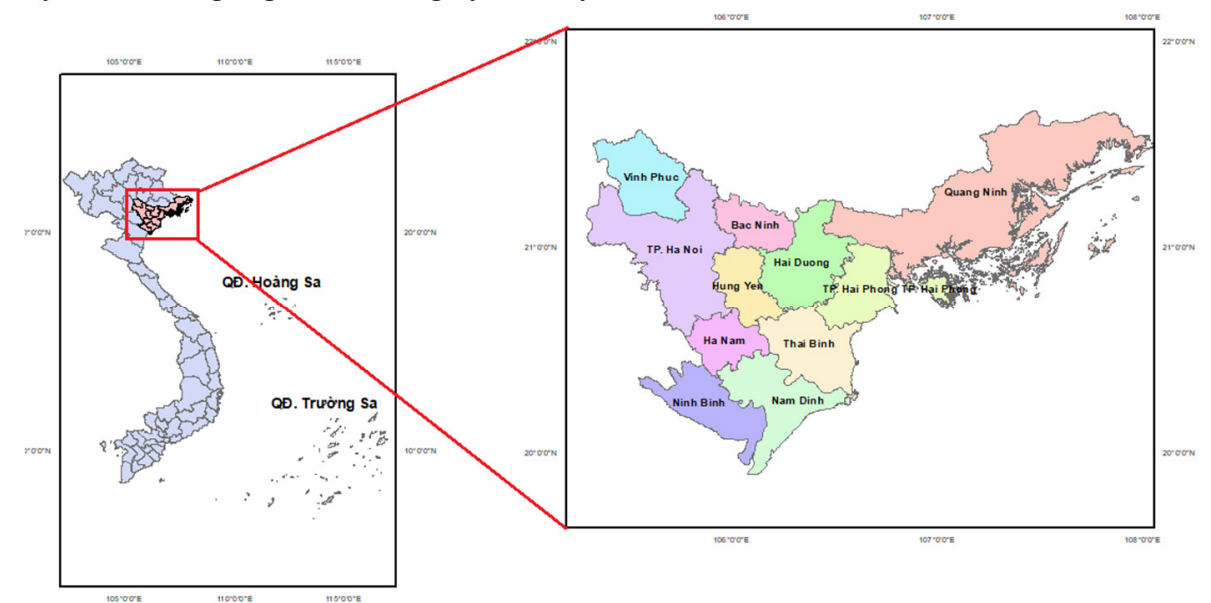

Hình 1. Vị trí địa lý vùng đồng bằng sông Hồng. 


\subsection{Phưong pháp nghiên cứu}

Trong kinh tế tài nguyên, giá trị kinh tế là thước đo số tiền tối đa mà một cá nhân sẵn sàng bỏ ra để có được một số hàng hoá và dịch vụ dựa trên lợi ích mà họ thu được từ hàng hoá hay dịch vụ đó. Sự đánh giá phúc lợi này là một sự nhấn mạnh thông thường trong khái niệm về mức sẵn lòng chi trả (Willing to pay - WTP). Ví dụ như, giá trị của nước đối với người sử dụng là số tiền tối đa mà người sử dụng sẽ sẵn sàng trả cho việc sử dụng tài nguyên.

Theo đó, nước là một nguồn tài nguyên có giá trị cho mọi sự sống và các quá trình phát triển kinh tế xã hội. Ngày nay, nhu cầu sử dụng nước ngày một cao, ngoài mục đích sinh hoạt, còn phục vụ cho phát triển các ngành kinh tế như năng lượng, công nghiệp, nông nghiệp, dịch vụ,... khiến nó trở thành nguồn tài nguyên có sự cạnh tranh khốc liệt trong khai thác sử dụng. Do vậy, vai trò của quản lý tài nguyên nước đang được nghiên cứu rất nhiều trong những thập kỷ qua. Kể từ sau hội nghị quốc tế Duplin về nước và môi trường năm 1992, cộng đồng khoa học đã thừa nhận quản lý hiệu quả nguồn nước bao gồm cả quản lý nước như một loại hàng hoá. Theo đó, đặc tính sử dụng nước được phân tích trên cả 3 yếu tố, giá trị của nước, chi phí sử dụng nước và chi phí cơ hội để sử dụng tài nguyên nước. Sự tồn tại của chi phí cơ hội sử dụng khác nhau làm thay đổi đặc tính "tự do" của nước và yêu cầu ưu tiên sử dụng nước. Uu tiên của giá trị nước được xác định trên cơ sở nhận thức về giá trị của nước và phản ánh trong các chính sách về nguồn nước [9-13].Có rất nhiều nghiên cứu về định giá nước cho công nghiệp $[5,14,15]$, nông nghiệp $[10-12,16]$ và sinh hoạt [17-18] theo hướng tiếp cận của mức sã̃n lòng chi trả từ phía cầu.

Trong nghiên cứu này, giá trị của nước được đánh giá qua mức sã̃n lòng chi trả của hộ sử dụng nước. Chi phí sử dụng nước là toàn bộ chi phí mà nhà sản xuất phải bỏ ra tạo ra thành phẩm cung cấp đến các hộ dùng nước, để sản xuất $\mathrm{ra} 1 \mathrm{~m}^{3}$ nước, bao gồm cả chi phí cơ hội cho sử dụng nước. Quy trình đề xuất định giá tài nguyên nước được trình bày trên hình 2 .

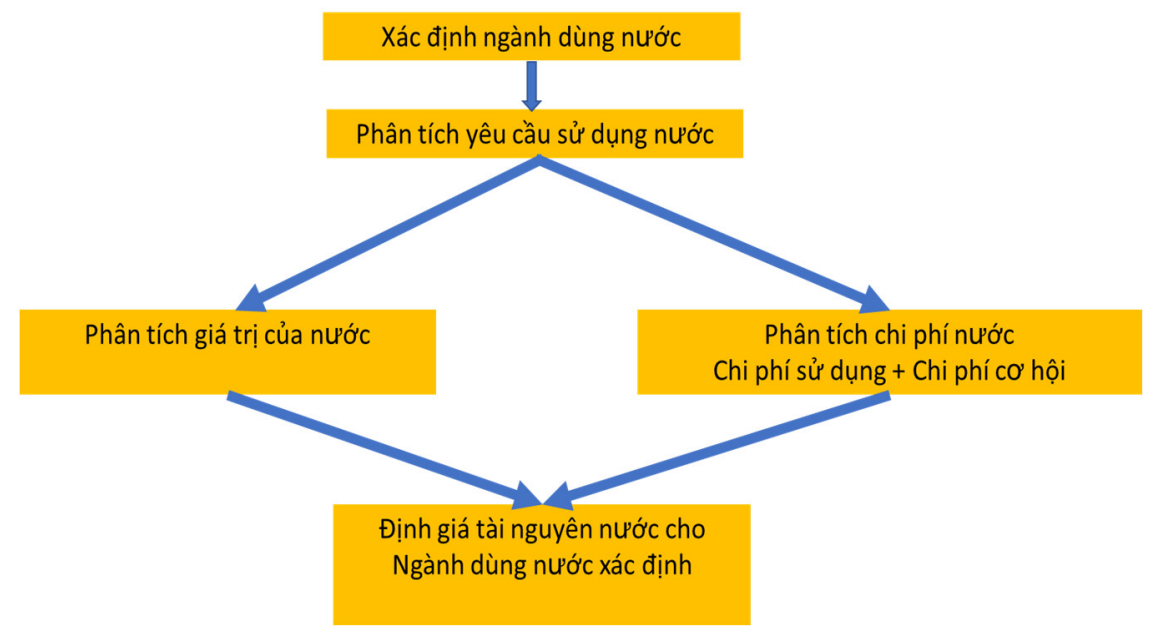

Hình 2. Quy trình định giá TNN cho một ngành dùng nước xác định.

Trong quy trình này, mỗi ngành dùng nước có các yêu cầu sử dụng nước khác nhau về số lượng và chất lượng. Từ đó dâ̂n đến việc nhận thức về giá trị của nước cũng khác nhau và đòi hỏi chi phí nước cũng khác nhau. Để phân tích giá trị của nước đối với từng ngành dùng nước, phương pháp tiếp cận là xác định mức sẵn lòng chi trả của các đối tượng dùng nước khác nhau, chi phí nước được xác định bởi các nhà sản xuất cung ứng nước.

- Mức sã̃n lòng chi trả được xác định dựa trên phương pháp đánh giá ngẫu nhiên CVM $[11,13,19]$. Về cơ bản, phương pháp này dựa trên điều tra khảo sát hộ dùng nước về mức sã̃n lòng chi trả của họ về lượng tài nguyên mà họ sử dụng. Mẫu phiểu điều tra được xây dựng dựa trên các đặc tính của hộ dùng nước và nguồn cung cấp nước như nhu cầu sử dụng 
nguồn nước đảm bảo cả về số lượng và chất lượng, giới tính, độ tuổi, lượng nước thường sử dụng hàng tháng, cách ứng phó với tình trạng khan hiếm nước, ô nhiễm nước, ,...

- Chi phí nước là chi phí từ phía cung, bao gồm cả chi phí đầu tư, sản xuất, phí tài nguyên và lợi nhuận yêu cầu từ phía nhà sản xuất. Chi phí này sẽ được xác định từ phía nhà cung ứng, và là một điểm giá khởi đầu để đưa vào bảng khảo sát mức sẵn lòng chi trả.

\subsection{1. Áp dụng quy trình trong định giá tài nguyên nước cấp công nghiệp}

Dựa trên quy trình đề xuất ở trên, định giá TNN cho sản xuất công nghiệp được thực hiện như sau:

B1. Xác định giá nước tù̀ bên cung cấp dịch vu

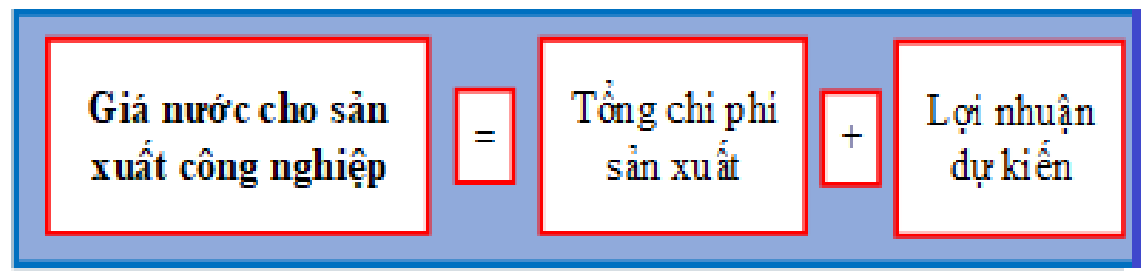

Hình 3. Công thức định giá nước cho sản xuất công nghiệp dựa trên tổng chi phí sản xuất và lợi nhuận dự kiến.

Trong công thức này, Tổng chi phí sản xuất gồm chi phí sản xuất trực tiếp, chi phí quản lý doanh nghiệp, chi phí bán hàng được xác định từ Thông tư số 25/2014/TT-BTC ngày 17 tháng 02 năm 2014 của Bộ Tài chính và Thông tư liên tịch số 75/2012/TTLT-BTC-BXDBNNPTNT ngày 15 tháng 05 năm 2012 của Liên Bộ Tài chính-Bộ Xây dựng-Bộ Nông nghiệp và Phát triển nông thôn.

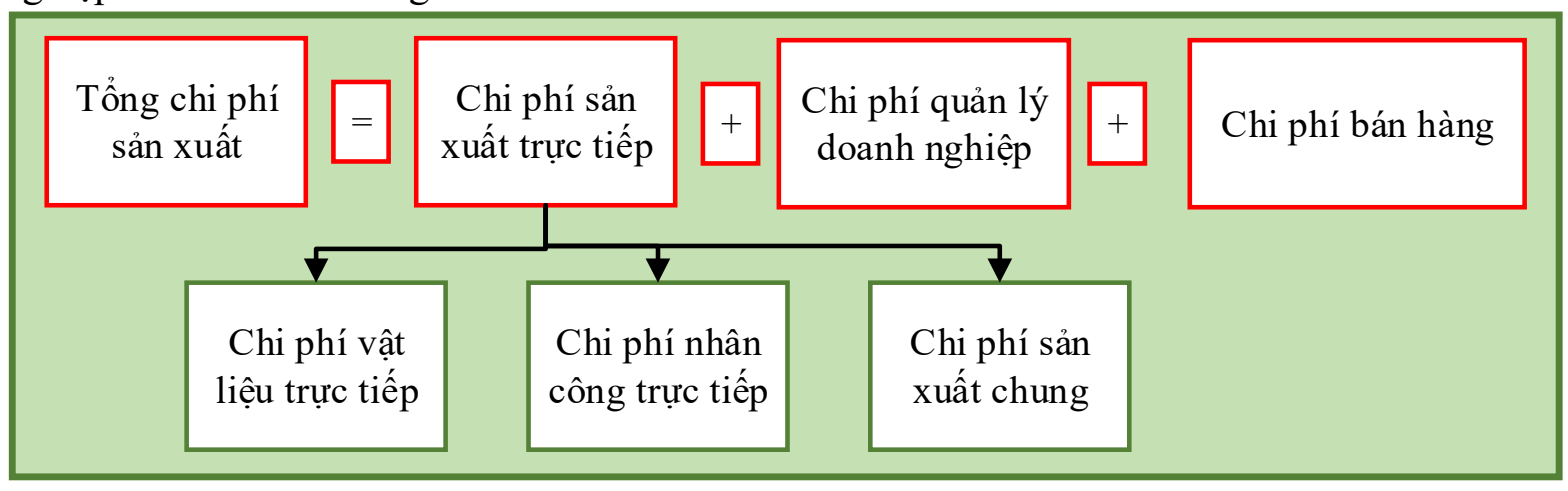

Hình 4. Công thức xác định Tổng chi phí sản xuất.

Giá thành toàn bộ $1 \mathrm{~m}^{3}$ nước sạch làm cơ sở tính giá nước sạch bình quân được xác định theo công thức sau:

$$
\mathrm{Z}_{\mathrm{tb}}=\frac{\mathrm{C}_{\mathrm{t}}}{\mathrm{SL}_{\mathrm{tp}}}
$$

Trong đó $\mathrm{Z}_{\mathrm{tb}}$ là giá thành toàn bộ $01 \mathrm{~m}^{3}$ nước sạch bình quân (đồng $/ \mathrm{m}^{3}$ ); $\mathrm{C}_{\mathrm{t}}$ là tổng chi phí sản xuất, kinh doanh nước sạch hợp lý, hợp lệ ứng với sản lượng nước thương phẩm (đồng); $\mathrm{SL}_{\text {tp }}$ là sản lượng nước thương phẩm, được xác định như sau:

$$
\mathrm{SL}_{\mathrm{tp}}=\mathrm{SL}_{\mathrm{sx}}-\mathrm{KL}_{\mathrm{hh}}
$$

Trong đó $\mathrm{SL}_{\mathrm{tp}}$ là sản lượng nước thương phẩm ( $\mathrm{m}^{3} /$ năm); $\mathrm{SL}_{\mathrm{sx}}$ là sản lượng nước sản xuất; KLhh là khối lượng nước hao hụt.

Lợi nhuận dự kiến tính toán theo quy định của Nhà nước. Theo đó tỷ suất lợi nhuận là tỷ lệ phần trăm $(\%)$ của khoản lợi nhuận tính trên giá thành toàn bộ và không được làm cho tổng giá lớn hơn giá thị trường. 


\section{B2. Xác định giá nước tù̀ bên sử dụng dịch vu}

Mức sẵn lòng chi trả của doanh nghiệp chính là số tiền mà người tiêu dùng sẵn lòng trả thêm để có được dịch vụ đảm bảo/tốt hơn về số lượng và chất lượng ngay cả trong các điều kiện cực đoan như $\mathrm{BĐKH}$ hay phát triển kinh tế xã hội làm suy giảm nguồn nước cấp. Trên quan điểm này, nghiên cứu tiến hành tham vấn ý kiến doanh nghiệp sử dụng nước với mức tham vấn ban đầu là giá nước hiện hành từ phía cung cấp dịch vụ (chi phí không thể giảm bớt) và người sử dụng có thể chi trả thêm bao nhiêu để có được nguồn cấp ổn định hoặc/và nâng cao chất lượng dịch vụ.

\subsection{2. Áp dụng quy trình trong định giá tài nguyên nước cấp nông nghiệp}

Theo quy định hiện hành của Nhà nước và cơ chế chính sách trong quản lý khai thác hệ thống thủy lợi, giá nước tưới phục vụ sản xuất nông nghiệp hiện nay gồm hai thành phần: (1) Giá nước tưới tính từ đầu mối công trình thủy lợi đến đầu kênh cấp hai (là khoản kinh phí cung cấp nước tưới từ phía công ty TNHH MTV KTCTTL) và (2) Chi phí cấp nước nội đồng cho sản xuất nông nghiệp từ phía Hợp tác xã (Hình 5).

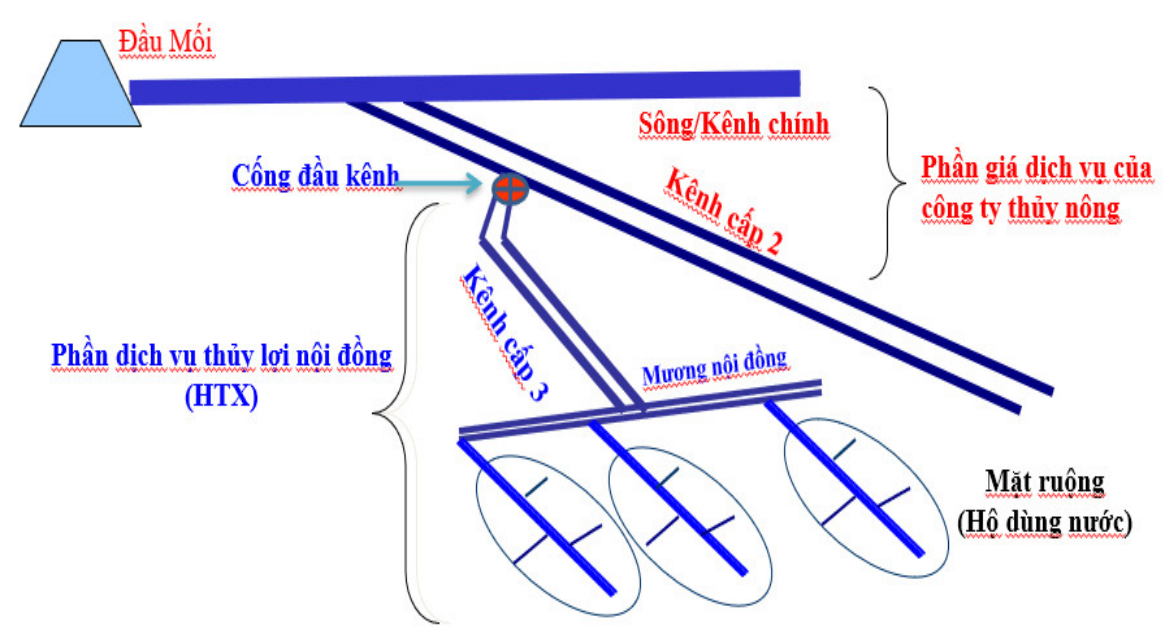

Hình 5. Sơ đồ hệ thống thủy lợi.

Trong đó giá nước tưới tính từ đầu mối công trình thủy lợi đến đầu kênh cấp hai được xác định dựa trên chi phí sản xuất của các công ty TNHH MTV KTCTTL theo nguyên tắc tính đúng, tính đủ và căn cứ vào các văn bản quy định hiện hành của Nhà nước. Phần giá này được Nhà nước chi trả cho các đơn vị quản lý hệ thống công trình thủy lợi và còn được gọi là giá thành của sản phẩm.

Chi phí cấp nước nội đồng cho sản xuất nông nghiệp là mức phí mà người sử dụng nước tưới phải bỏ ra để đưa nước tưới từ hệ thống kênh chính, kênh cấp hai về công trình kênh, mương, rạch, đường ống dẫn nước tưới, tiêu nước trong phạm vi từ điểm giao nhận sản phẩm, dịch vụ thủy lợi đển khu đất canh tác. Theo đó, đề xuất định giá nước cho sản xuất nông nghiệp được tính toán theo theo 2 bước sau:

B1. Xác định giá nuớc tù̀ bên cung cấp dịch vu

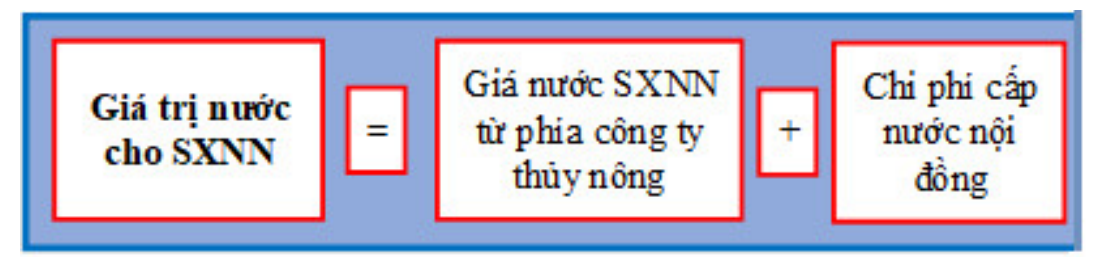

Hình 6. Các thành phần của giá trị nước cho sản xuất nông nghiệp theo phía cung cấp dịch vụ. 
Trong đó Giá nước $\mathrm{SXNN}$ từ phía công ty thủy nông được tính bằng phương pháp hạch toán chi phí, gồm các thành phần sau: giá thành sản xuất, lợi nhuận dự kiến (nếu có), các nghĩa vụ tài chính theo quy định của pháp luật (nếu có) như hình 7.

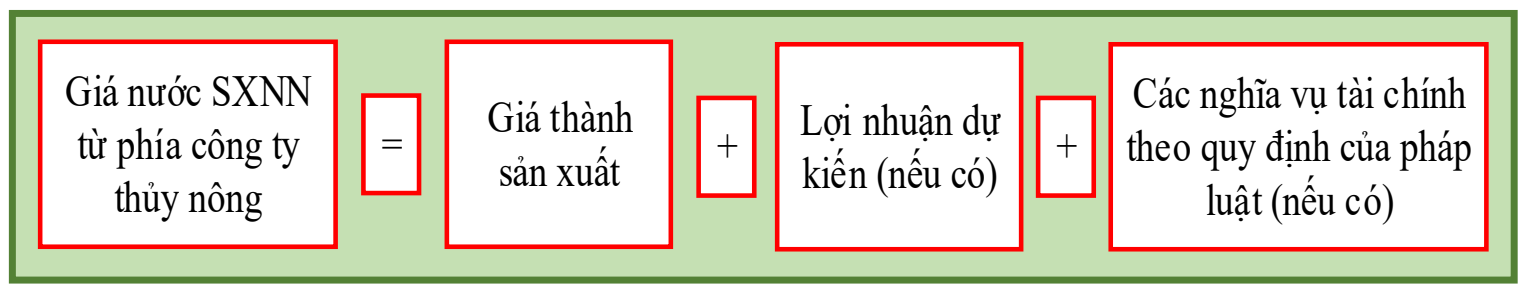

Hình 7. Phương pháp xác định giá nước SXNN từ phía công ty thủy nông.

- Chi phí cấp nước nội đồng được xác định từ Quyết định của UBND tỉnh.

\section{B2. Xác định giá nước tù bên sủ dụng dịch vụ}

- Mức sẵn lòng chi trả của người sử dụng dịch vụ được xác định bằng phương pháp định giá ngẫu nhiên $(\mathrm{CVM})$ thông qua điều tra người sử dụng dịch vụ với giá tham khảo khởi điểm là giá nước hiện hành tại địa phương (được xác định ở $\mathrm{B} 1$ ) và tham vấn về giá tăng thêm mà người dân có thể sẵn sàng chi trả để có nguồn nước cấp ổn định kể cả trong điều kiện cực đoan.

2.2.3. Áp dụng quy trình trong định giá tài nguyên nước cấp sinh hoạt

Đối với sinh hoạt, công thức xác định giá nước sinh hoạt tương tự như trường hợp nước cấp công nghiệp (hình 5). Theo đó,

- Giá thành sản xuất và lợi nhuận được xác định bởi bên cung ứng nước. Giá thành này trong thời điểm hiện tại sẽ là mức giá khởi điểm để điều tra mức sẵn lòng chi trả của các hộ dùng nước ở bước sau.

- Mức sẵn lòng chi trả được tính toán dựa trên các phiếu điều tra theo phương pháp CVM cho các đối tượng sử dụng nước khác nhau. Mẫu phiếu điều tra được thiết kế trên cơ sở phát triển từ giá nước hiện hành với các yếu tố nội tại và ngoại lai xuất hiện như: nâng cao chất lượng dịch vụ cung ứng, trong điều kiện khan hiếm nước, tác động của $\mathrm{B} Đ K H$ đến nhu cầu dung nước... Sau đó, mức sẵn lòng chi trả trung bình được đề xuất tính theo công thức (3).

$$
\mathrm{WTP}=\mathrm{C}+\beta_{1} \mathrm{X}_{1}+\beta_{2} \mathrm{X}_{2}+\beta_{3} \mathrm{X}_{3}+\beta_{4} \mathrm{X}_{4}+\beta_{5} \mathrm{X}_{5}+\beta_{6} \mathrm{X}_{6}
$$

Trong đó $\mathrm{WTP}$ là mức sẵn lòng chi trả; $\mathrm{X}_{1}$ là tuổi của người được phỏng vấn; $\mathrm{X}_{2}$ là giới tính của người được phỏng vấn; $X_{3}$ trình độ học vấn của người được phỏng vấn; $X_{4}$ thu nhập của hộ gia đình; $X_{5}$ lượng nước sử dụng bình quân hàng tháng của cả gia đình; $X_{6}$ biến đồi khí hậu; $C$ là hệ số chặn của mô hình hồi quy; $\beta_{1}, \beta_{2}, \beta_{3}, \beta_{4}, \beta_{5}, \beta_{5}$ là các hệ số tương ứng của các biến.

\section{Kết quả và thảo luận}

\section{1. Định giá tài nguyên nước cấp công nghiệp}

Áp dụng quy trình và phương pháp đề xuất ở hình 3 để xác định giá nước cấp công nghiệp điển hình cho tỉnh Nam Định cho thấy, chi phí sản xuất trung bình khoảng $13.500 \mathrm{~d} / \mathrm{m}^{3}$ nước. 


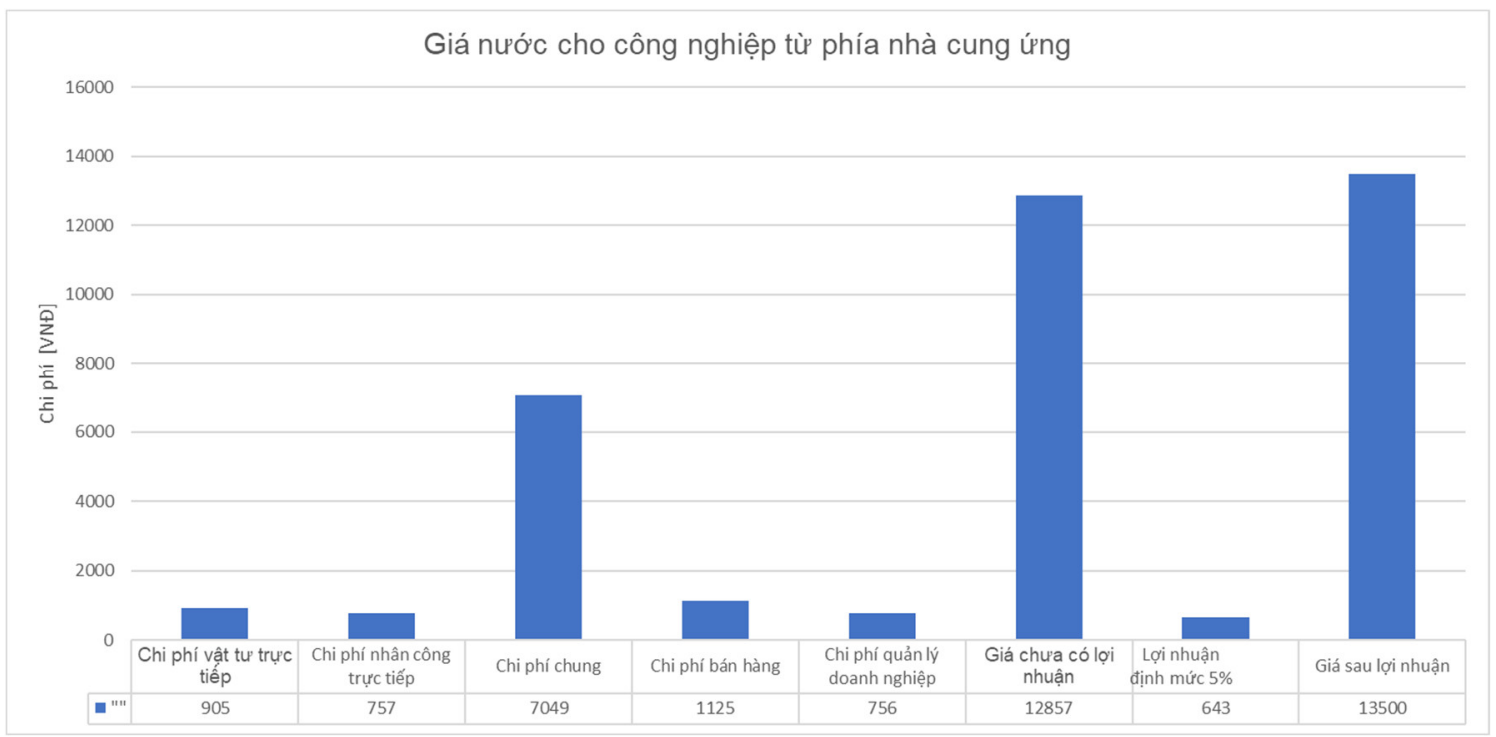

Hình 8. Giá nước từ phía nhà cung ứng.

Hình 8 cho thấy trong các loại chi phí, chi phí chung là loại chi phí lớn nhất, chi phí này bao gồm vốn đầu tư, chi phí duy tu bảo dưỡng định kỳ, phí khai thác tài nguyên và phí xả thải. Chi phí này chiếm trên $50 \%$ tổng giá nước cung ứng. Tiếp đến là chi phí bán hàng bao gồm cả tiền lương, bảo hiểm và phụ cấp cho cán bộ công nhân viên; chi phí sản xuất trực tiếp; chi phí nhân công trực tiếp và chi phí quản lý doanh nghiệp đều chiếm dưới $10 \%$ giá thành phẩm. Lợi nhuận chiếm $5 \%$ trên giá thành phẩm. Như vậy, tổng mức giá cung ứng là $13.500 \mathrm{~d} / \mathrm{m}^{3}$ nước cấp công nghiệp.

Mức sẵn lòng chi trả được xác định theo phương CVM cho 13 công ty sản xuất công nghiệp ở Nam Định, theo đó, mức trung bình mà các công ty sẵn lòng chi trả thêm là $10 \%$ tổng giá thành phẩm hiện tại để có được dịch vụ tốt hơn trong hiện tại. Do vậy giá nước cấp công nghiệp trong thời điểm hiện tại là $14.850 \mathrm{~d} / \mathrm{m}^{3}$.

Trong điều kiện BĐKH, khi nguồn nước cấp bị suy giảm, với giả định chi phí giữ nguyên hiện tại (giá thành vật tư, nhân công,... không có biến động theo thời gian) sẽ tăng lên $30 \%$ thành $19.279 \mathrm{~d} / \mathrm{m}^{3}$ nước trong giai đoạn 2030 và $70 \%$ thành $25.211 \mathrm{~d} / \mathrm{m}^{3}$ nước trong giai đoạn 2050 (Hình 9).

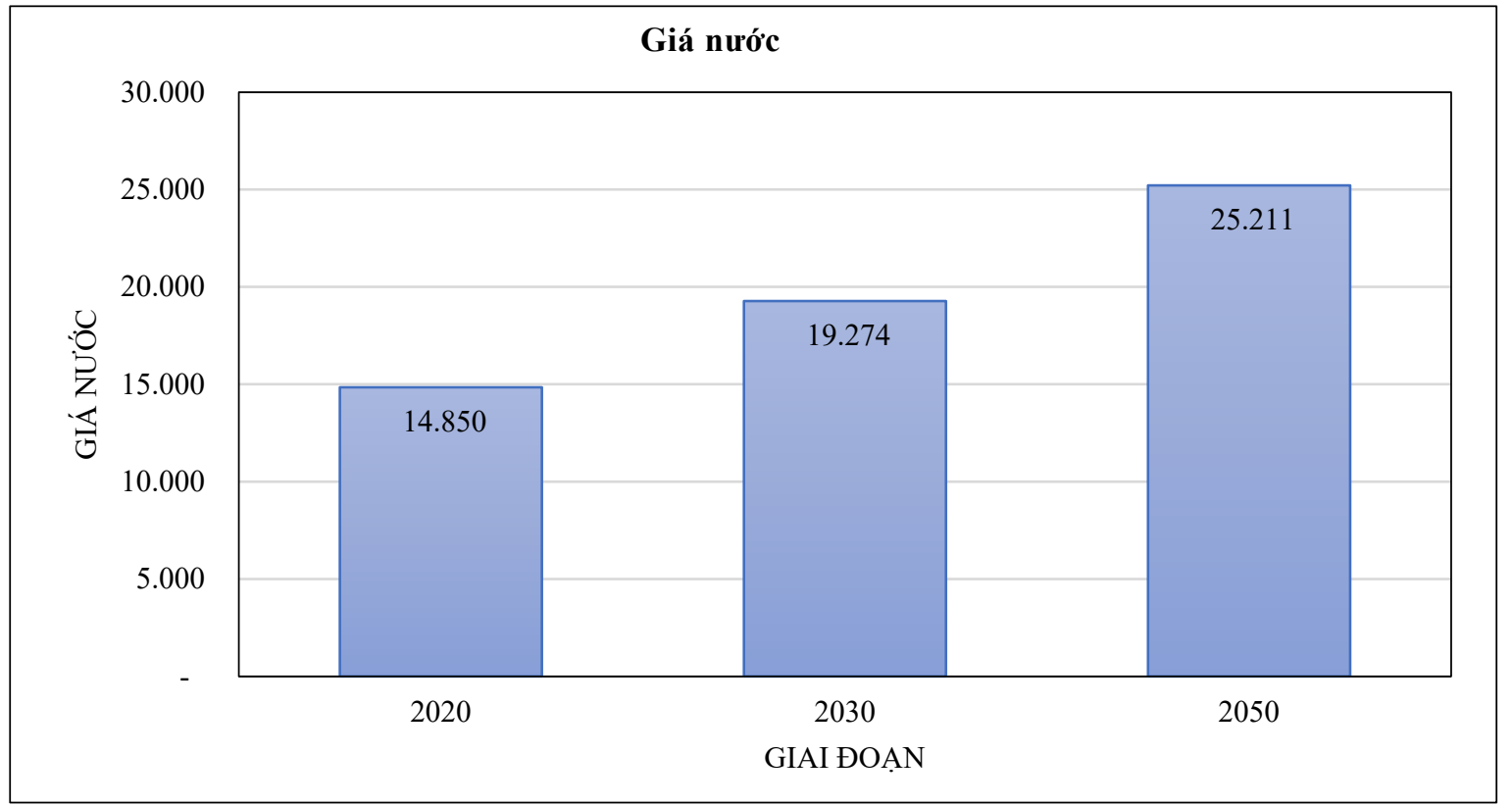

Hình 9. Giá nước theo các giai đoạn. 


\section{2. Định giá tài nguyên nước cấp nông nghiệp}

Áp dụng quy trình và phương pháp đề xuất ở hình 6 để xác định giá nước cấp nông nghiệp. Các loại hình sản xuất nông nghiệp chính vùng đồng bằng sông Hồng bao gồm trồng lúa, trồng màu, cây công nghiệp, làm muối và nuôi trồng thuỷ sản. Ngoài ra, phí tiêu thoát nước nông thôn cũng được tích hợp trong giá nước để duy tu bảo dưỡng hệ thống. Hình 10 thể hiện giá nước cho một $\mathrm{m}^{3}$ nước cấp cho loại hình sản xuất nông nghiệp khác nhau.

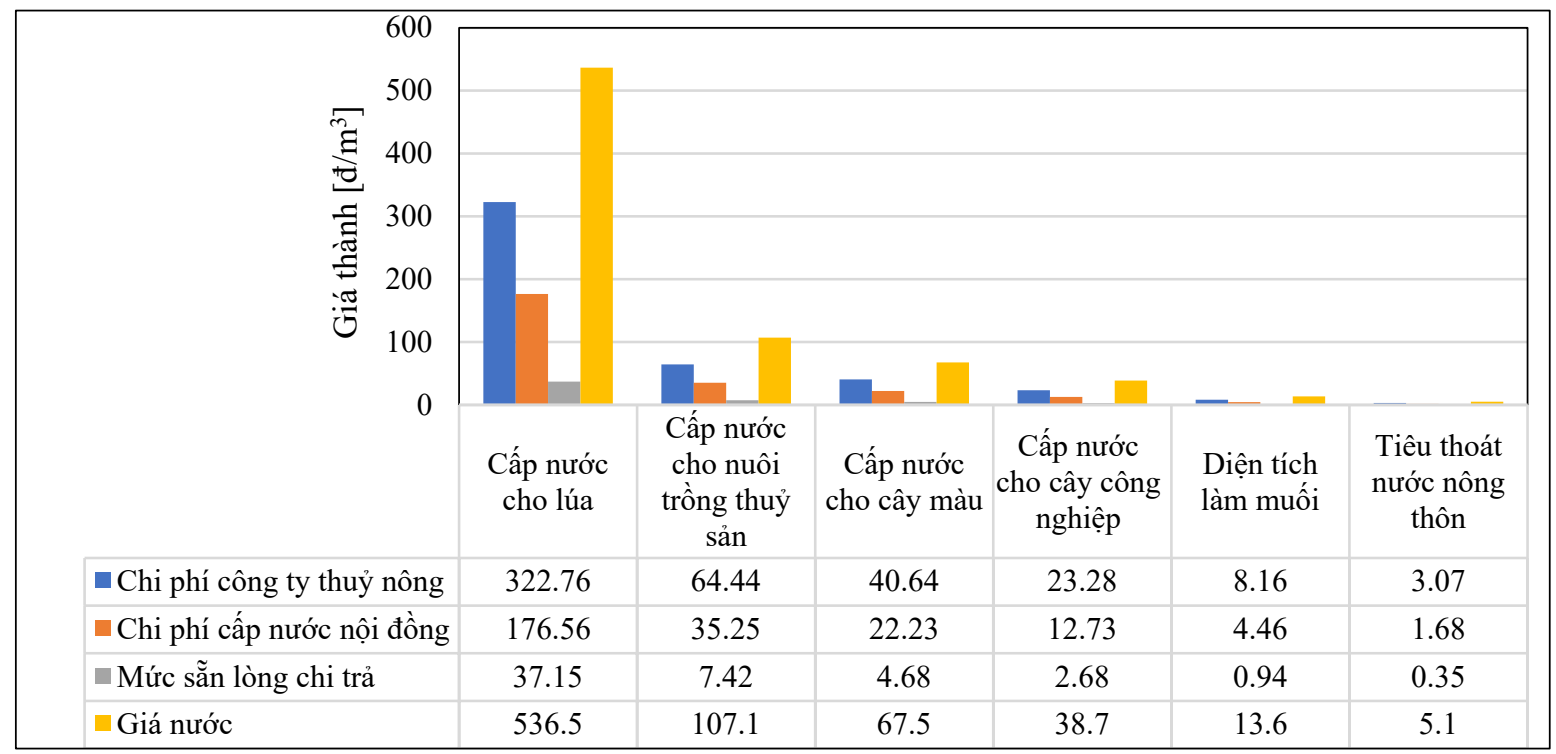

Hình 10. Giá $1 \mathrm{~m}^{3}$ nước cấp cho sản xuất công nghiệp.

Hình 10 cho thấy phân bổ chi phí của nước cấp nông nghiệp, trong đó chi phí công ty thuỷ nông là cao nhất, sau đó đến chi phí cấp nước nội đồng bằng khoảng $50-60 \%$ chi phí của công ty thuỷ nông. Mức sẵn lòng chi trả của các hộ dùng nước giao động khoảng trên dưới $10 \%$ chi phí cấp nước nội đồng. Cùng từ hình này cho thấy, nước cấp cho lúa có giá thành cao nhất, do nhu cầu sử dụng nước của loại cây trồng này lớn kéo theo chi phí sản xuất lớn. Tiếp đến là nước cho nuôi trồng thuỷ sản, cấp nước trồng màu và cây công nghiệp. Giá nước cho làm muối là nhỏ nhất. Nếu tính chi phí cho cấp nước tưới cho một ha sản xuất nông nghiệp, kết quả được thể hiện ở hình 11 .

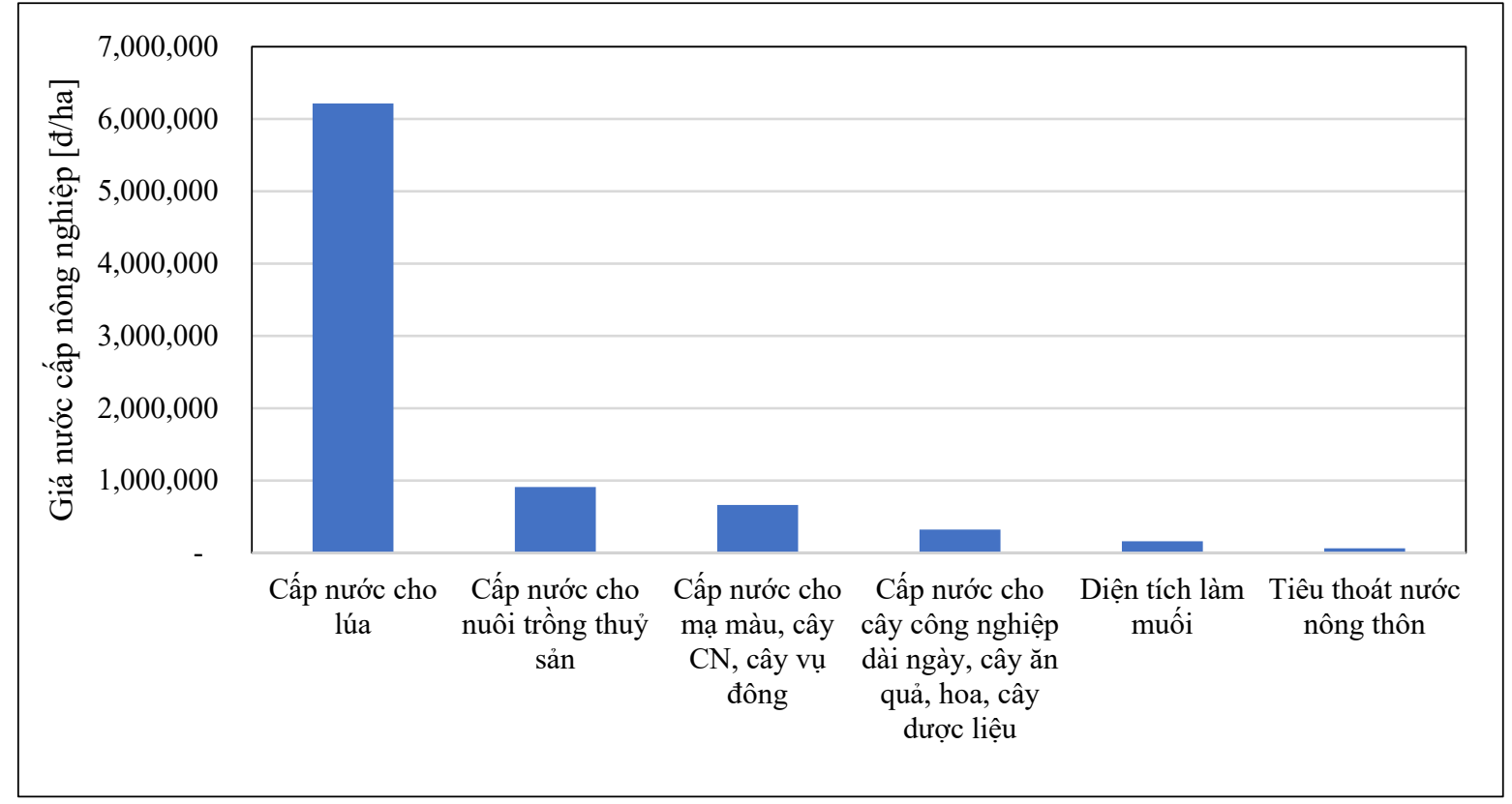

Hình 11. Giá nước trên 1 ha sản xuất nông nghiệp trong 1 năm. 
Theo đó, giá nước cấp cho ruộng lúa là cao nhất, khoàng 3.300 .000 triệu đồng/ha/ năm, tiếp đến là nuôi trồng thuỷ sản, khoảng trên $490.000 / \mathrm{ha} /$ năm; trồng màu khoàng $350.000 / \mathrm{ha} / \mathrm{năm}$. Chi phí cho cấp nước trồng cây công nghiệp là khoảng $170.000 \mathrm{~d} / \mathrm{ha} / \mathrm{năm}$, làm muối khoảng $90.000 \mathrm{~d} / \mathrm{ha} /$ năm và duy tu bảo dưỡng hệ thống tiêu thoát nước khoảng 30.000 đ/ha/năm. Trong điều kiện $\mathrm{B} Đ K H$, khi nhiệt độ và lượng mưa thay đổi, nhu cầu sử dụng nước cấp nông nghiệp cũng thay đổi, từ đó giá thành phẩm nước cấp công nghiệp cũng thay đổi. Theo đó, đến giai đoạn 2030 và 2050, giá nước của hầu hết các loại hình sản xuất nông nghiệp đều tăng gấp đôi.

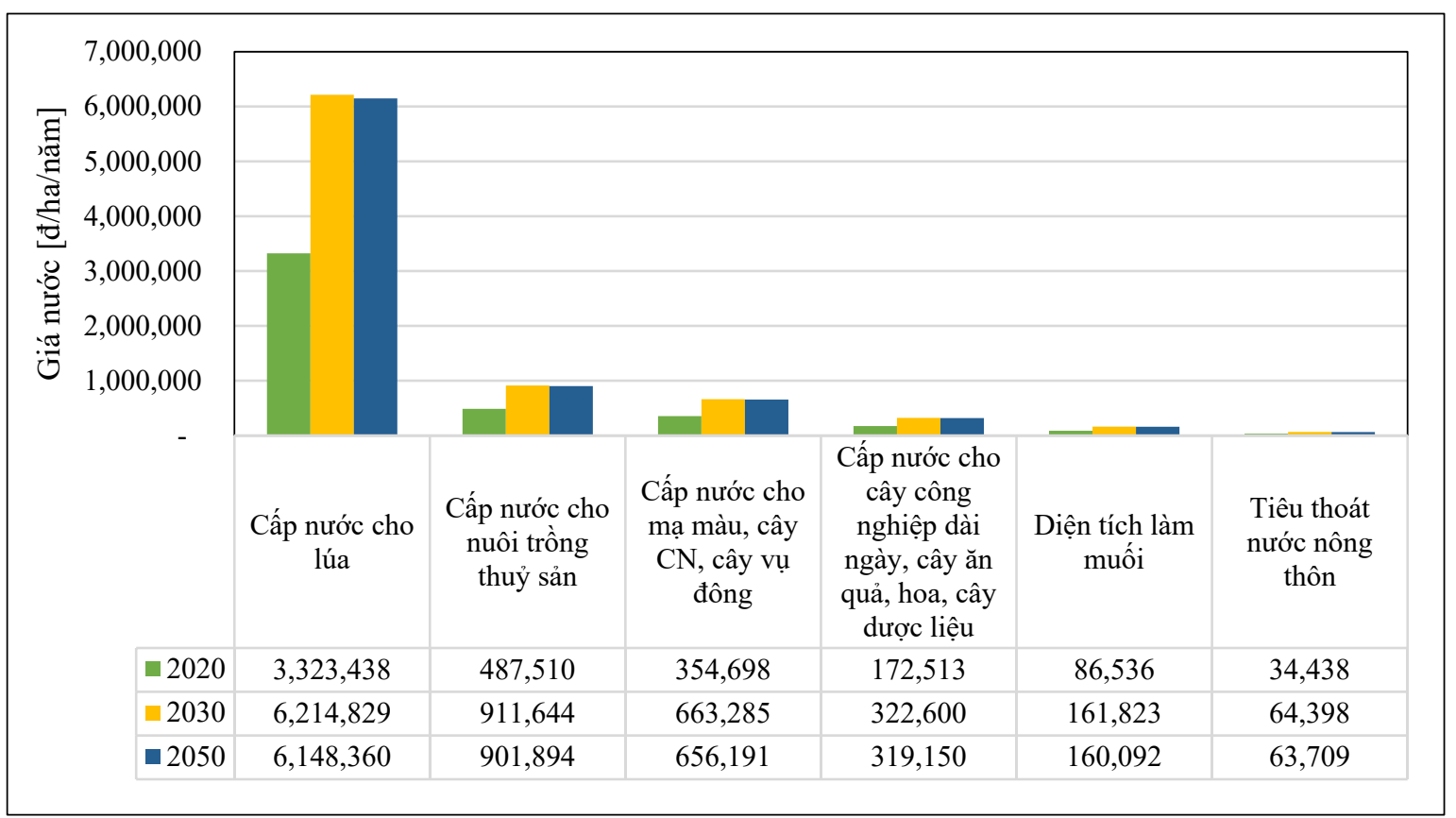

Hình 12. Giá nước cho sản xuất nông nghiệp theo các giai đoạn.

\section{3. Định giá tài nguyên nước cấp sinh hoạt}

Áp dụng quy trình đề xuất ở hình 3 , tiến hành tính toán giá nước sinh hoạt điển hình cho tỉnh Nam Định. Chi phí sản xuất cho các loại hình nước cấp sinh hoạt và sản xuất khác nhau được thể hiện ở hình 13.

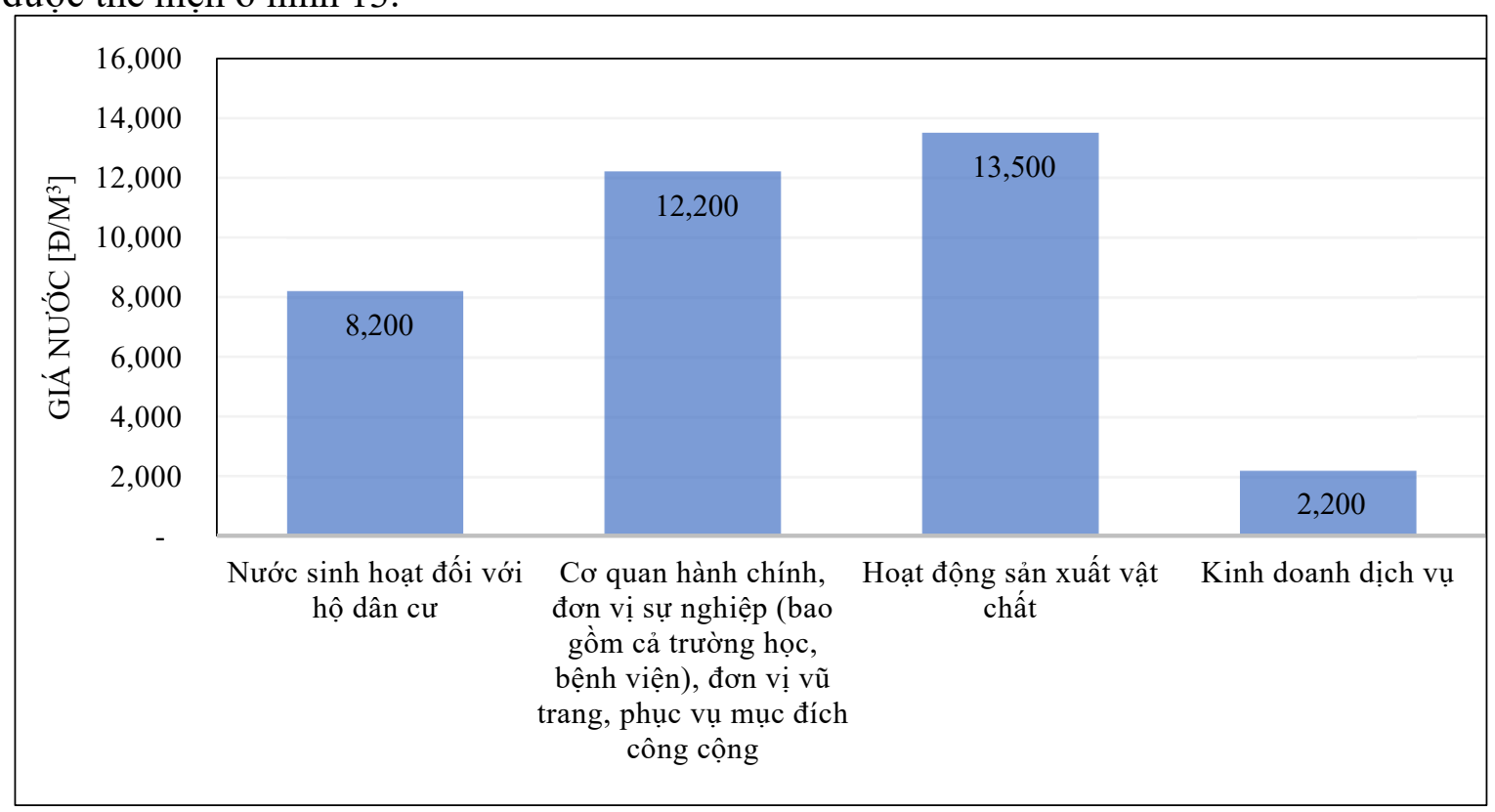

Hình 13. Giá nước của nhà cung ứng tính theo tổng chi phí thành phẩm. 
Về mức sẵn lòng chi trả tính trên phía nhu cầu, áp dụng công thức (3) xác định được mức sẵn lòng chi trả của hộ đã sử dụng nước máy và chưa sử dụng nước máy trên địa bàn thông qua tính toán thống kê trên số mẫu phiếu điều tra như sau:

$\mathrm{WTP}_{\text {hộ đang sử dụng nước máy }}=16468,97-17,864$ Age $-230,014 \mathrm{Gen}-186,81 \mathrm{Edu}-197,94 \mathrm{Inc}$ $-55,81 \mathrm{X}+1,49 \mathrm{Cli}$

Và

$\mathrm{WTP}_{\text {hộ chưa sử dụng nước máy }}=8785,62-23,36 \mathrm{Age}-482,83 \mathrm{Gen}+117,12 \mathrm{Edu}+534,60 \mathrm{Inc}$ $+224,65 \mathrm{X}+41,13 \mathrm{Cli}$

Trong đó $\mathrm{C}$ là hệ số hiệu chỉnh; Age là biến độ tuổi; Gen là biến giới tính; Edu là biến học vấn; Inc là biến thu nhập; X là lượng nước sử dụng; Cli là biến khí hậu.

Các biến này sau khi được thu thập trên phiếu điều tra đều được chuẩn hoá về thang giá trị như nhau từ $0-1$. Kết quả cho thấy, đối với hộ đang sử dụng nước máy, các biến ảnh hưởng lớn nhất là giới tính, trình độ và thu nhập có ảnh hưởng nhiều hơn cả. Biến ảnh hưởng của $\mathrm{BĐKH}$ có ảnh hưởng rất ít đến giá thành mà người sử dụng sẵn sàng chi trả. Tuy nhiên đối với những hộ chưa sử dụng nước máy, ngoài giới tính, độ tuổi và thu nhập, lượng nước sử dụng cũng là biến quan trọng để xác định mức sẵn lòng chi trả. Kết quả tính toán cho thấy mức sẵn lòng chi trả của hộ đã sử dụng nước máy là $13.163 \mathrm{~d} / \mathrm{m}^{3}$ nước, cao hơn gần $20 \% \mathrm{so}$ với mức giá hiện tại để có thể có được dịch vụ cung cấp nước tốt hơn. Đối với hộ chưa sử dụng nước máy là 12.414 đồng/ $\mathrm{m}^{3}$.

\section{Kết luận}

Nghiên cứu này đã đề xuất được quy trình xác định giá nước cho 3 ngành dùng nước chính vùng đồng bằng sông Hồng trong điều kiện $\mathrm{BĐKH} \mathrm{bao} \mathrm{gồm} \mathrm{sinh} \mathrm{hoạt,} \mathrm{công} \mathrm{nghiệp} \mathrm{và}$ nông nghiệp. Quy trình này cho phép xác định từng thành phần trong xác định giá trị của nước bao gồm: giá trị của nước được xác định từ phía cầu thông qua nghiên cứu mức sẵn lòng chi trả của các hộ dung nước trên hệ thống; và tổng chi phí sản xuất bao gồm chi phí sử dụng và chi phí cơ hội tích hợp tính toán từ phía cung. Kết quả cho thấy, mức sẵn lòng chi trả từ phía người sử dụng dịch vụ trong trường hợp nước cấp sản xuất giao động trong khoảng trên dưới $10 \%$, tuy nhiên đối với nước cấp sinh hoạt là $20 \%$. Trong điều kiện $\mathrm{BĐKH,} \mathrm{giá}$ nước tăng do nguồn cung giảm, có thể lên đến hơn $50 \%$ như trường hợp nước cấp công nghiệp và nông nghiệp.

Đóng góp của tác giả: Xây dựng ý tưởng nghiên cứu: N.N.T., T.V.A.; Lựa chọn phương pháp nghiên cứu: N.N.T., T.V.A., H.T.H., D.V.Q.; Thu thập, phân tích, tính toán xử lý số liệu: N.D.D., V.N.L., B.A.T.; Viết bản thảo bài báo: T.V.A.; Chỉnh sửa bài báo: N.N.T., H.T.H., D.V.Q.

Lời cảm ơn: Bài báo này là kết quả nghiên cứu của đề tài "Định giá tài nguyên nước đồng bằng sông Hồng trong bối cảnh biến đổi khí hậu”, mã số TNMT.2018.02.16 của trường Đại học Tài Nguyên và Môi trường Hà Nội, do PGS.TS. Nguyễn Ngọc Thanh làm chủ nhiệm.

Lời cam đoan: Tập thể tác giả cam đoan bài báo này là công trình nghiên cứu của tập thể tác giả, chưa được công bố ở đâu, không được sao chép từ những nghiên cứu trước đây; không có sự tranh chấp lợi ích trong nhóm tác giả.

\section{Tài liệu tham khảo}

1. 2030 Water Resources Grooup. Việt Nam: Khuôn khổ kinh tế về nước để đánh giá các thách thức của ngành nước. Géopolitique des ressources minières en Asie du Sud-Est 2017, 189-236. http://dx.doi.org/10.2307/j.ctt1f116fp.9.

2. Grafton, R.Q.; Garrick, D.E.; Horne, J. Water Misallocation: Governance Challenges and Responses, 2017, pp.1-51. Online available: https://www.researchgate.net/publication/331297130_Water_Misallocation_Gover nance_Challenges_and_Responses. 
3. Butterworth, J.; Warner, J.; Moriarty, P.; Smits, S.; Batchelor, C. Finding practical approaches to integrated water resources management. Water Altern. 2010, 3(1), 6881.

4. Allan, J.A. Virtual water: a long term solution for water short Middle Eastern economies?. London Sch. Orient. African Stud. Univ. London 1997, 9, 24-29. Online available: http://www.ciaonet.org/wps/aln02/.

5. Anand, P.B. Scarcity, Entitlements and the Economics of Water in Developing Countries. Cheltenham, UK: Edward Elgar Publishing, 2007.

6. Inglezakis, V.J.; Poulopoulos, S.G.; Arkhangelsky, E.; Zorpas, A.A.; Menegaki, A.N. Chapter 3 - Aquatic Environment. Environ. Dev. 2016, 137-212.

7. Narasimhan, S. Water Pricing: Potential And Problems. Int. J. Agric. Econ. Manag. 2016, 6, 1, 5-8. Online available: http://www.ripublication.com.

8. Tổng cục thống Kê. Niên giám thống kê, 2019.

9. Briscoe, J. Water as an economic good: the idea and what it means in practice. World Congr. Int. Comm. Irrig. Drain. 1996, 9, 177-202.

10. Namyenya, A.; Sserunkuuma, D.; Bagamba, F. Willingness to pay for irrigation water and its determinants among rice farmers at Doho Rice Irrigation Scheme (DRIS) in Uganda. J. Dev. Agric. Econ. 2014, 6(8), 345-355. http://dx.doi.org/ 10.5897/jdae2014.0580.

11. Alemayehu, T. Smallholder Farmer's Willingness to Pay for Improved Irrigation Water: A Contingent Valuation Study in Koga Irrigation Project, Ethiopia. J. Econ. Sustain. Dev. 2014, 5(19), 5-16.

12. Mallios, Z.; Latinopoulos, P. Willingness to pay for irrigation water: A case study in Chalkidiki, Greece. Proc. $7^{\text {th }}$ Int. Conf. Environ. Sci. Technol. Vols a B, 2001, 566573.

13. Boman, M. Applying the Contingent Valuation Method in Resource Accounting: A Bold Proposal, 2003.

14. Li, K. Dynamic optimization of input production factors for urban industrial water supply and demand management. J. Environ. Manage. 2020, 270, 110807. http://dx.doi.org/10.1016/j.jenvman.2020.110807.

15. WWF Germany. Linking water risk and financial value - Part 3: New valuation tool and database, 2019, pp. 20. Online Available: https://d2ouvy59p0dg6k.cloudfront.net/downloads/wwf_waterrisk_financialvalue_ part3_web.pdf.

16. Leyva, J.C.; Sayadi, S. Economic valuation of water and willingness to pay analysis in tropical fruit production in South-Eastern Spain. Spanish J. Agric. Res. 2005, 3(1), 25. http://dx.doi.org/10.5424/sjar/2005031-121.

17. Al-Saidi, M. Urban water pricing in Yemen: a comparison of increasing block tariffs to other pricing schemes. Water Int. 2017, 42(3), 308-323. http://dx.doi.org/10.1080/02508060.2016.1269283.

18. "Pricing Urban Water_Principles and Compromises.pdf." .

19. Arrow, K.; Solow, R.; Portney, P.R.; Leamer, E.E.; Radner, R.; Schuman, H. Report of the NOAA Panel on Contingent Valuation. Fed. Regist. 1993, 58(10), 4601-4614.

20. Thông tư số 25/2014/TT-BTC ngày 17 tháng 02 năm 2014 của Bộ Tài chính.

21. Thông tư liên tịch số 75/2012/TTLT-BTC-BXD-BNNPTNT ngày 15 tháng 05 năm 2012 của Liên Bộ Tài chính-Bộ Xây dựng-Bộ Nông nghiệp và Phát triển nông thôn. 


\title{
Water pricing in the Red River Delta under climate change condition
}

\author{
Truong Van Anh ${ }^{*}$, Nguyen Ngoc Thanh ${ }^{1}$, Hoang Thi Hue ${ }^{1}$, Do Van Quang ${ }^{2}$, Nguyen \\ Duc Duong', Bui Anh Tu², Vu Ngoc Luan² \\ ${ }^{1}$ Hanoi University of Nature resources and Environment; nnthanh@hunre.edu.vn; \\ tvanh@hunre.edu.vn; hthue@hunre.edu.vn \\ 2 Thuy Loi University; quangkttl@tlu.edu.vn
}

\begin{abstract}
Water is a special natural resource which is essential for all life on earth but also necessary for the development of many key economic sectors on the world. Water is also the receiving sources of waste, then becomes so contaminated and no longer capable of supplying other water requirements, causing water scarcity due to socio-economic development even where is abundant water resources. Pricing water resources is one of the tools to help policy makers manage water resources in a more sustainable way by balancing production costs, including waste treatment costs, and the future investigation cost to be able to get better water services in the future. This paper proposes a method for pricing water resources in the Red River Delta, taking into account the impacts of climate change on the costs and opportunities of water use for industry, agriculture and domestic water supply.
\end{abstract}

Keywords: Water pricing; Climate change; Water resources management; Economic water use; Willing to pay. 